\title{
Corner Cut Microstrip Patch Antenna for Ultra Wide BandApplications
}

\author{
Mr.Abhishek Karwa ${ }^{1}$, Ms. Shweta Kumari ${ }^{2}$, Ms. Supriya Sharma \\ ${ }^{I}$ Asst. Professor, Dept. of ECE, JIET School of Engg. and Technology for Girls Jodhpur, Rajasthan, INDIA \\ ${ }^{2}$ Sudent, Dept. of ECE, JIET School of Engg. and Technology for Girls Jodhpur, Rajasthan, INDIA \\ ${ }^{3}$ Student, Dept. of ECE, JIET School of Engg. and Technology for Girls \\ Jodhpur, Rajasthan, INDIA
}

\begin{abstract}
In this paper, the radiation performance of a small printedmicro strip antennadesigned on glass epoxy FR4 substrate discussed. The proposed antenna is capable to cover Wi MAX, Wi Fi, WBAN and Bluetooth operations and UWB applications. The Simulated results for various parameters like radiation patterns, total field gain, return loss, VSWR, radiation efficiency etc. are also calculated with high frequency structure simulator HFSS. Its simulate results display impedance bandwidth from $3.04 \mathrm{GHz}$ to $10.96 \mathrm{GHz}$ the antenna complies with the return loss of $S_{11}$ less then $-10 \mathrm{db}$ and VSWR $<2$ throughout the impedance bandwidth.
\end{abstract}

Keywords: Ultra-Wide Band, Multiband Band, Patch antenna

\section{Introduction}

FCC (Federal communications commission) allocated a block of radio spectrum from $3.1 \mathrm{GHz}$ to 10.6 $\mathrm{GHz}$ for UWB operations [1].UWB systems can support more than $500 \mathrm{Mbps}$ data transmission within 10m [2]. Compact size, low-cost printed antennas with Wideband and Ultra wideband characteristic are desired in modern communications. The Ultra wide band antennas can be classified as directional and Omni-directional antennas [3]. A directional antenna have the high gain and relatively large in size. It has narrow field of view. Whereas the omni-directional antenna have low gain and relatively small in size. It has wide field of view as they radiates in all the directions [4].

The UWB antennas have broad band. There are many challenges in UWB antenna design. One of the challenges is to achieve wide impedance bandwidth. UWB antennas are typically required to attain a bandwidth, which reaches greater than $100 \%$ of the center frequency to ensure a sufficient impedance match is attained throughout the band such that a power loss less than $10 \%$ due to reflections occurs at the antenna terminals. Various planar shapes, such as square, circular, triangular, and elliptical shapes are analyzed [5].Compared with monopole based planar antennas, the design of ultra wide band circular ring type antennas is difficult because of effect of the ground Plane.

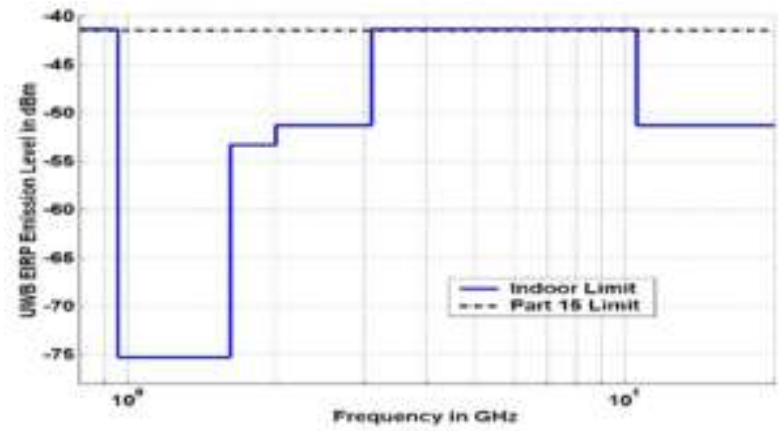

Fig. 1 UWB Spectral Mask per FCC (Modified) Part 15 Rules [1]

\section{Antenna Configuration And Design}

For patch antenna the length and width are used as calculated from the equations. The expression for $\varepsilon_{\text {reff }}$ is given by Balanis as [8]

$$
\begin{aligned}
& \qquad \varepsilon_{\text {reff }}=\frac{z_{x}+1}{2}+\frac{z_{r}-1}{2}\left[1+12 \frac{\mathrm{h}}{\mathrm{w}}\right]^{1 / 2} \\
& \text { The effective length of the patch } L_{\text {eff }} \text { now bocomes: } \\
& \mathrm{L}_{\text {eff }}=\mathrm{L}+2 \Delta \mathrm{L}
\end{aligned}
$$


The dimensions of the patch along its length have now been extended on each end by a distance $\Delta \mathrm{L}$, which is given empirically by Hammerstad as:

$$
\Delta \mathrm{L}=0.412 h \frac{\left(s_{\text {reff }}+0.3\right)\left(\frac{W}{h}+0.264\right)}{\left(s_{\text {reff }}-0.258\right)\left(\frac{W}{h}+0.8\right)}
$$

For a given resonance frequency $f_{o}$, the effective length is given by

$$
\mathrm{L}_{\text {eff }}=\frac{c}{2 f_{0} \sqrt{\varepsilon_{\text {reff }}}}
$$

For a rectangular microstrip patch antenna, the resonance frequency for TM mn mode is given by James and Hall as-

$$
f_{0}=\frac{c}{2 \sqrt{s_{\text {reff }}}}\left[\left(\frac{m}{L}\right)^{2}+\left(\frac{n}{W}\right)^{2}\right]^{1 / 2}
$$

For efficient radiation, the width $\mathrm{W}$ is given by -

$$
W=\frac{c}{2 f_{0} \sqrt{\frac{\varepsilon_{r}+1}{2}}}
$$

The motivation of UWB antenna is to design a small and simple omnidirectional antenna that introduces low distortions with large bandwidth. The corner cut shaped antenna presented is fabricated on a 25mm x18 mm 1.6-mm-thick FR4 board.

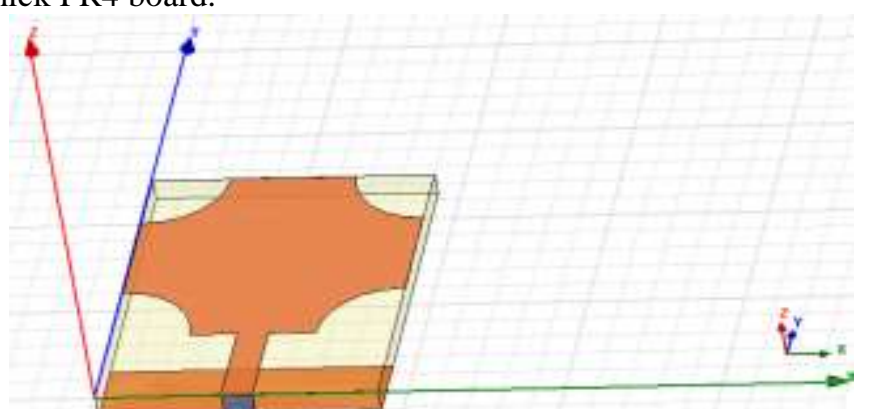

Fig. 2 Geometry of rectangular patch corner cut antenna

The proposed antenna designed on a FR-4 substrate with dielectric constant $\varepsilon r=4.4$ and height of the substrate is $\mathrm{h}=1.6 \mathrm{~mm}$. The substrate has length $\mathrm{L}=18 \mathrm{~mm}$ and width $\mathrm{W}=25 \mathrm{~mm}$.

Vacuum box has length $\mathrm{L}=73.38 \mathrm{~mm}$, width $\mathrm{W}=18 \mathrm{~mm}$ and height $\mathrm{H}=49.98 \mathrm{~mm}$

\section{Simulation Results}

This antenna is suitable for operating frequency $3.04 \mathrm{GHz}$ to $10.96 \mathrm{GHz}$ allotted by IEEE 802.16 working group for UWB applications. The VSWR obtained is less than 2 the patch antenna is found to have the compact size and 90\% Maximum Fractional Bandwidth. The return loss value of band is $-19.82 \mathrm{~dB}$ at $10 \mathrm{GHz}$. We can obtain the higher values of return loss and VSWR and antenna offers excellent performance in the range of $3.9 \mathrm{GHz}-10.96 \mathrm{GHz}$ rather than various different shapes antennas used in this range. The VSWR, total field gain $1.462 \mathrm{~dB}$, directivity 1.542 , incident power $100 \%$, E and $\mathrm{H}$ fields at $10 \mathrm{GHz}$ are also calculated in Fig. 5 to Fig. 13 respectively.

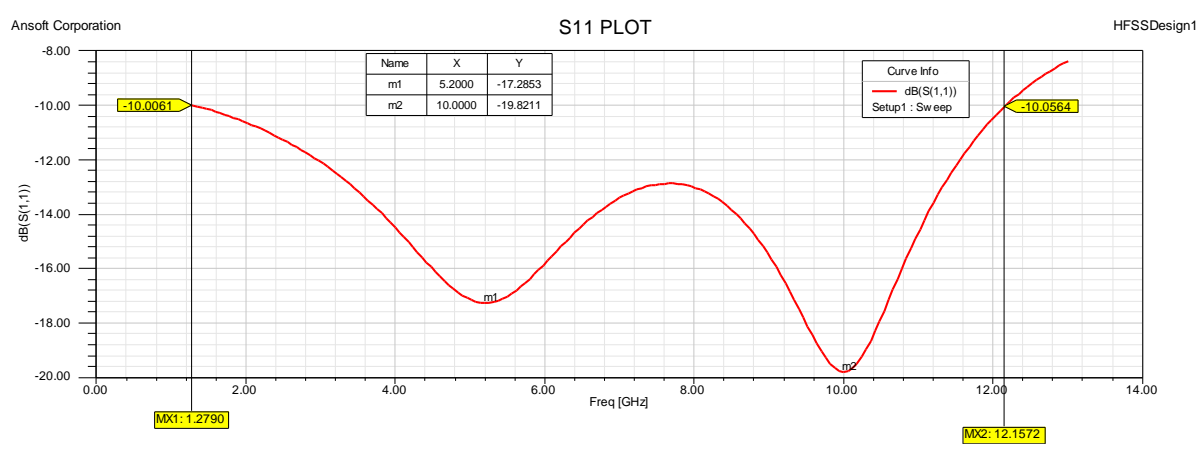

Fig. 3 Return Loss Curve 


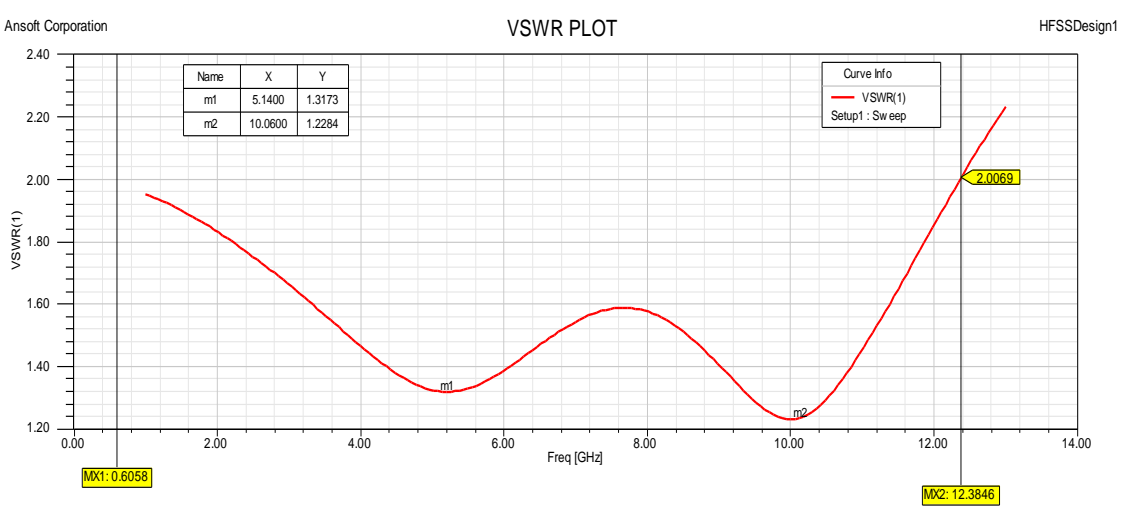

Fig. 4 VSWR value of the antenna
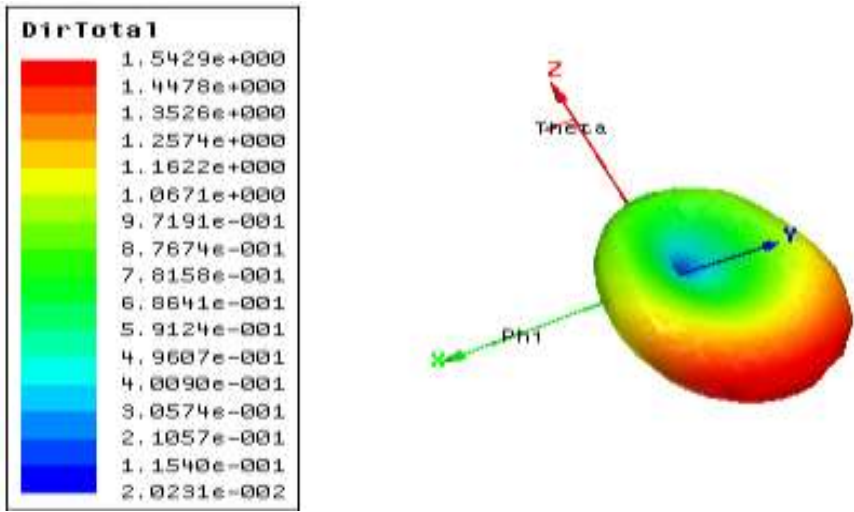

Fig. 5 Directivity of antenna is 1.5429

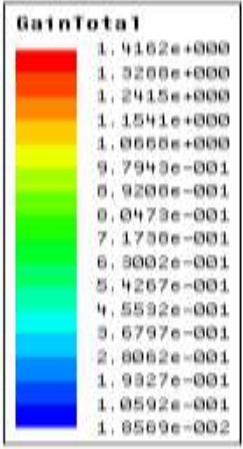

Fig. 6 Gain of micro strip patch antenna is $1.4162 \mathrm{~dB}$

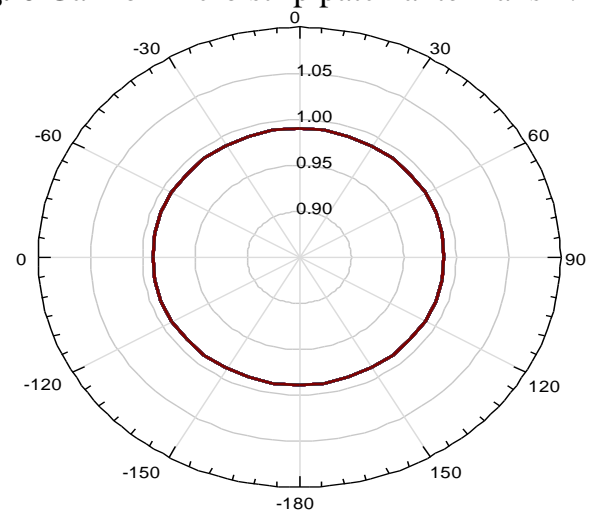

Fig. 7 Accepted Power at different 'Phi' (10GHz) 


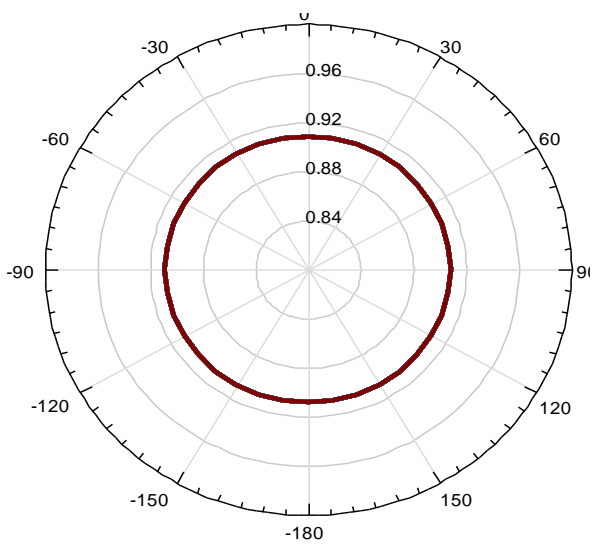

Fig. 8 Radiated power at different 'Phi' (10GHz)

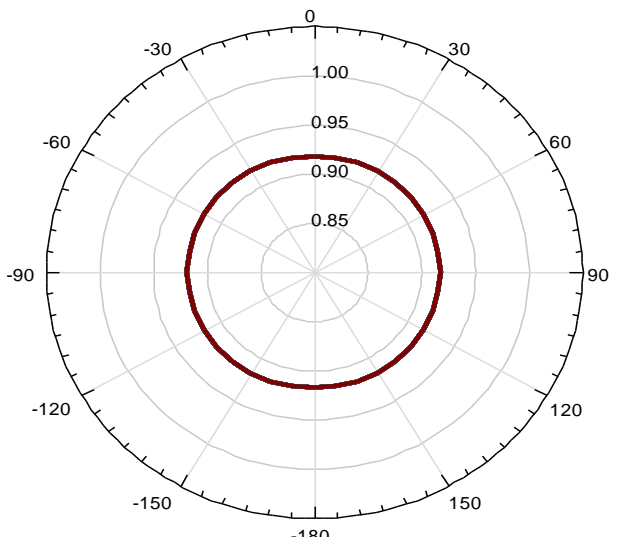

Fig. 9 Radiation Efficiency at different 'Phi' (10GHz)

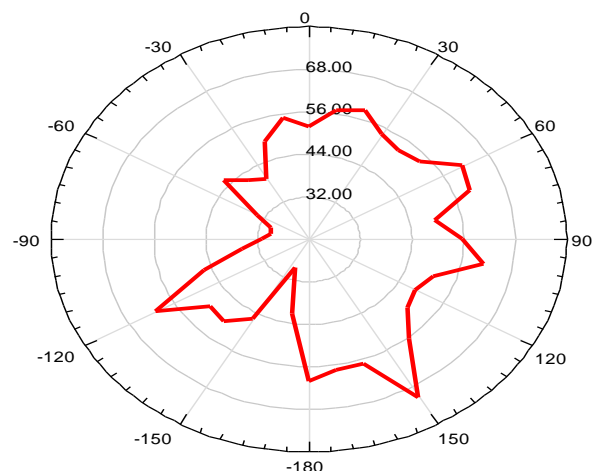

Fig. 10 Axial ratio of the antenna

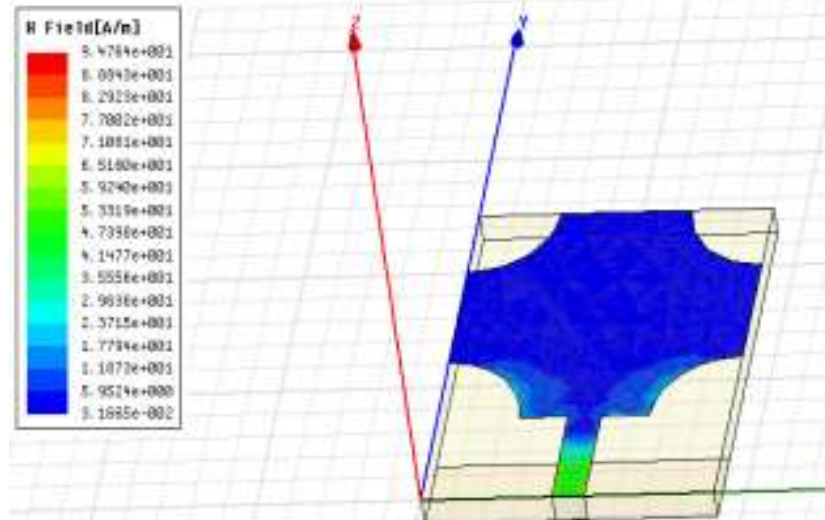

Fig. 12 Electric field of the antenna 


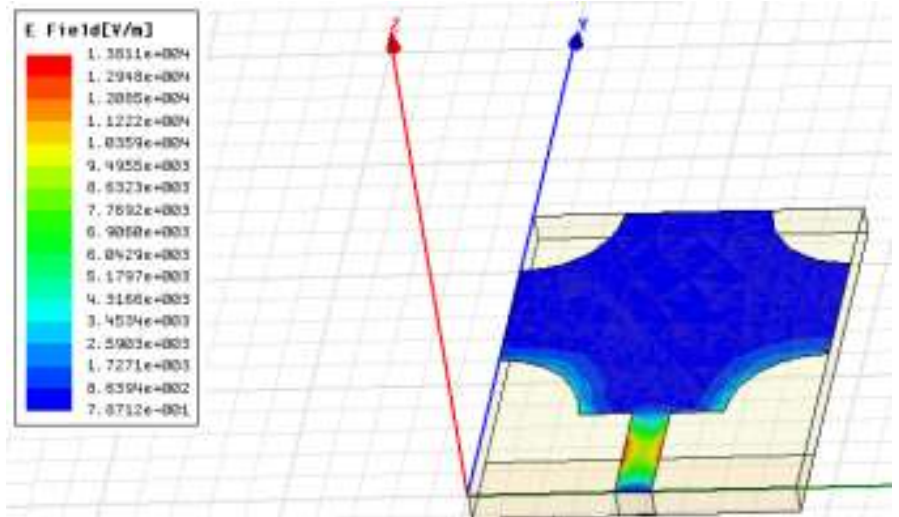

Fig. 13 Magnetic field of the antenna

\section{Fabrication}

The antenna structure is fabricated on a printed circuit board (PCB) using Photolithography technique.

\section{Conclusion}

The fabricated antenna has advantages of small size, easy fabrication and simple construction. Antenna operates at $3.04 \mathrm{GHz}-10.96 \mathrm{GHz}$ with Absolute Bandwidth $10.8782 \mathrm{GHz}$. Radiation performance of patch antenna is also presented in this paper. The simulated results indicate that an ultra-wide band antenna with Maximum Fractional Bandwidth $90 \%$ can be achieved by removing corners of rectangular micro strip patch antenna. The directivity of an antenna is 1.5429 and gain is $1.462 \mathrm{~dB}$ and we conclude that proposed geometry is applicable for ultra-wide band from $3.1 \mathrm{GHz}$ to $10.6 \mathrm{GHz}$.In future the Radiation performance this rectangular patch antenna can be improved by using different feeding techniques.

\section{Acknowledgements}

The authors thanks to Mr. Jitendra Jagid Asst. Professor (Sr.), JNU Jodhpur for guidance and Entuple Technology Pvt. Ltd., Bengaluru for providing HFSS simulation facility, and Circuitronix, Gujarat for fabrication process.

\section{Proceedings Papers:}

\section{References}

[1]. FCC report and order for part-15 acceptance of ultra-wide band systems (UWB) from 3.1 to $10.6 \mathrm{GHz}$, washington, DC,2002

[2]. Ashish Mathur ,Deepak Sharma,Geetika Mathur "Design and Simulation of Dual Band Patch Antenna for Ultra Wide Band (UWB) Applications Using HFSS, ICMARS2012- Jodhpur, Volume 1, Issue 1 pp.771-774, December 11-15, 2012

[3]. Ashish Mathur ,Deepak Sharma,Geetika Mathur "Design and Simulation of Rectangular and Half Ring Patch Antenna for Ultra Wide Band (UWB) Applications Using HFSS, ICMARS2012- Jodhpur, Volume 1, Issue 1 pp.296-300, December 11-15, 2012

[4]. Ashish Mathur ,Deepak Sharma,Geetika Mathur "Design and Simulation of Dual Band Patch Antenna for ISM, WI-MAX and CBand Rejection Using HFSS" in International Conference in Advancement on Information Technology (ICAIT), Souvenir March 22-23, 2013.

[5]. Prof. P.S.Ashtankar and Dr.C.G.Dethe "Design and Modification of Circular Monopole UWB Antenna for WPAN Application Computer Engineering and Intelligent Systems ISSN 2222-1719 (Paper) ISSN 2222-2863 (Online) Vol 3, No.5, 2012

[6]. Priya Upadhyay, Richa Sharma "Design and Implementation of Series Micro Strip Patch Antenna Array For Wireless Communication” Int.J. Computer Technology \& Applications, Vol 3 (5), 1769-1774 ISSN: 2229-6093 Sept-Oct 2012

[7]. Shelly Chawla, Jagtar Singh, Paras Chawla "Single to Multiband Frequency Technique for Wireless and Telecomm Microstrip Antenna Design" International Journal of Soft Computing and Engineering (IJSCE) ISSN: 2231-2307, Volume-2, Issue-5, November 2012

[8]. Radouane Karli and Hassan Ammor "Design of Microstrip Patch Antenna for 3.6 GHz WIMAX Applications " European Journal of Scientific Research ISSN 1450-216X Vol. 88 No 4, pp.556-564, October, 2012.

[9]. Zhao, C.-planar IEEE Antennas andWireless Propagation Letters, Vol. 3, 2004

[10]. Hosseini, S. A., Z. Atlasbaf, acompact ultra wide band (UWB) planar antenna using Journal of Electromagnetic Wavesand Applications, Vol. 22, No. 1, 47 59, 2008.

[11]. Ma, T.-G. and C. - An-ultra wideband coplanar waveguide-fed tape Transactions on Antennas and Propagation, Vol. 54, No.4, April 2006.

[12]. Chair, R., A. A. Kishk, K. F. Lee, C. E. Smith, and D.Kajfez,antennas with U-shaped tuning stub and Progress In Electromagnetic Research, PIER 56, 163182, 2006.

Books:

[13]. C. Balanis, Antenna Theory: Analysis and Design, New York, John Wiley \& Sons, Inc., 1997. 